\title{
Erosion-corrosion resistance of engineering materials in various test conditions
}

\author{
S.S. Rajahram*, T.J. Harvey, R.J.K. Wood \\ national Centre for Advanced Tribology at Southampton, School of Engineering Sciences, University of Southampton Highfield, \\ Southampton SO17 1BJ, UK
}

\section{A R T I C L E I N F O}

\section{Article history:}

Received 16 September 2008

Received in revised form 5 January 2009

Accepted 5 January 2009

\section{Keywords:}

Slurry pot erosion tester

Erosion-corrosion

Error analysis

Synergy

\begin{abstract}
A B S T R A C T
Erosion-corrosion is a complex phenomenon which involves the interaction between the mechanical processes of solid particle erosion and the electrochemical processes of corrosion. A whole range of issues is faced by a designer when trying to obtain relevant information on erosion-corrosion performance of a material. Amongst the constraints are the dispersed test conditions and test rigs available in the literature making comparisons and quantifying erosion-corrosion wear rates of different materials very difficult. The aim of this work is to evaluate the repeatability of erosion-corrosion experiments and to investigate the role of different parameters influencing erosion-corrosion. The materials tested in this work are stainless steel (SS316L/UNS S31603), carbon steel (AISI 1020/UNS G10200) and nickel-aluminium bronze (NAB/UNS C63200). A slurry pot erosion tester was used as the test apparatus and test parameters such as erodent size, erodent concentration, flow velocity and test solutions were varied to study their effect on erosion-corrosion. SEM analysis showed that a similar erosion-corrosion mechanism is seen for SS316L and NAB with formation of multiple extruded lips and platelets typically seen for erosion dominated material. In contrast the surface of AISI 1020 revealed the formation of craters, pits and shallow indentations which suggests that corrosion mechanism has a dominant influence on the material. Error rates in tests were found to have an average of $5.5 \%$ which are relatively low indicating good repeatability of test measurements and data from the test rig. The erosion-corrosion resistance of AISI 1020, SS316L and NAB were compared and it was found that SS316L showed the lowest erosion-corrosion mass loss rates in all test conditions followed by NAB and then AISI 1020. However in terms of synergistic ranking, $\mathrm{NAB}$ showed the best resistance to the combined action of erosion and corrosion with the highest negative synergy value. Positive synergy was evident for AISI 1020 in $3.5 \% \mathrm{NaCl}$ and SS316L in $0.3 \mathrm{M} \mathrm{HCl}$. A wear map is presented to evaluate erosion-corrosion trends of the materials. This work combines the assessment of test repeatability, variation in test conditions and comparison of material performance which are key stages in a material selection process.
\end{abstract}

(c) 2009 Elsevier B.V. All rights reserved.

\section{Introduction}

Wear caused by solid particle erosion-corrosion has received significant attention amongst researchers in recent years due to the severity of the problems caused by this phenomenon to components in service, resulting in material loss and subsequent equipment failure. Erosion-corrosion related problems occur in power plants, oil and gas processing plants and chemical plants where there is an interaction between solid particles, corrosive fluid and a target material. The problem has been reported to affect static equipment for example pipelines, valves, heat exchangers, pressure vessels and various rotating equipment namely compressors, turbines and pumps. The importance of material selection for

\footnotetext{
* Corresponding author. Tel.: +44 238052 7667; fax: +44 2380593230 .

E-mail address: ssr1y07@soton.ac.uk (S.S. Rajahram).
}

applications in these environment cannot be overstated as component wear can be accelerated by the aggressive conditions in these harsh environments. Synergy is the additional wear rate experienced by a metal under the combined action of erosion-corrosion conditions which is higher than the sum of wear rate due to pure erosion and flow corrosion [1-3]. This factor can reduce the service life of engineering material significantly. The interactions of these two processes are complex in nature, therefore, careful material characterization in terms of its erosion resistance, corrosion resistance and synergy effect has to be understood for appropriate material selection in any engineering application.

Synergism as described earlier is the difference between the combined erosion-corrosion wear rate and the sum of pure erosion and pure corrosion acting separately and can be expressed by Eq. (1).

$S=T-(E+C)$ 
where $T$ is the total wear rate due to erosion-corrosion, $E$ is the wear rate due to pure erosion, $C$ is the wear rate due to flow corrosion and $S$ is the additional wear rate due to the synergistic interaction between erosion and corrosion. Synergism consists of two main components which is the erosion enhanced corrosion rate $(\Delta C)$ and the corrosion enhanced erosion rate $(\Delta E)$ shown in Eq. (2).

$S=\Delta E+\Delta C$

The complexity of the erosion-corrosion phenomena is not only limited to the interaction between the various parameters affecting erosion and corrosion. A whole range of issues is faced by the designer when trying to obtain relevant information on erosion-corrosion performance of a material. It would be ideal if the testing of material under erosion-corrosion conditions could be done in the field to obtain accurate data on material performance. However, this is economically and practically unviable. Researchers and designers have to rely on information obtained from laboratory-based erosion-corrosion experiments. The constraint is often the various laboratory experiments are very specific in terms of tests conditions and environments. The need for standardization of erosion-corrosion testing is crucial. The first step towards standardization is selecting a suitable rig which can produce repeatable results. By embarking on this, test conditions could be reproduced every time, giving confidence in the results when varying parameters in experiments.

In order to determine the total wear rate caused by the combined effect of erosion and corrosion, various rigs have been designed to measure this effect. Amongst these rigs are slurry pot erosion tester [4-9], jet impingement rig [10-14], Coriolis erosion tester [15-17], pipe flow loop [18,19] and rotating cylinder apparatus [20-22]. Each rig has its advantages and disadvantages in terms of ease of usage, cost, ease of maintenance and control of test parameters. Laboratory simulation of erosion-corrosion testing is often scaled down to predict actual field conditions. The pipe flow loop provides a good indication of actual erosion-corrosion rates in slurry pipelines but is seldom used due to the high cost of construction, maintenance and actual space limitation within laboratories. A slurry pot erosion tester was selected for this work as it allows variation of parameters with good accuracy [4-9]. Erosion-corrosion testing is performed with this rig by changing the slurry medium to corrosive slurry.

The current work involves a comparison of engineering materials to study their sensitivity to parameters like flow velocity, sand size, sand concentration and test solutions. It is vital that these parameters are well understood and evaluated in a controlled condition to determine the synergistic effect that arises from erosion-corrosion. A set of experiments was performed to compare erosion-corrosion resistance of a passive and active material in a controlled environment. This work also aims to provide quantitative information on the applicability of the slurry pot erosion tester to obtain repeatable results. The multiple tests performed provide useful information on the percentage error and confidence level of each test. Error analysis is important in evaluating erosion-corrosion data. For synergy, the error is calculated using Eq. (3).

$\sigma_{S}=\sqrt{\sigma_{C}^{2}+\sigma_{E}^{2}+\sigma_{T}^{2}}$
Table 2

Surface roughness of the test samples.

\begin{tabular}{llll}
\hline Surface roughness & SS316L & AISI 1020 & NAB \\
\hline$R_{\mathrm{a}}$ & $0.28 \pm 0.04 \mu \mathrm{m}$ & $0.21 \pm 0.04 \mu \mathrm{m}$ & $0.51 \pm 0.06 \mu \mathrm{m}$ \\
\hline
\end{tabular}

Table 3

Sand optical analysis [24].

\begin{tabular}{lllll}
\hline & & Coarse & Medium & Fine \\
\hline Size $(\mu \mathrm{m})$ & 3D & $665 \pm 49$ & $294 \pm 43$ & $106 \pm 41$ \\
& Section & $553 \pm 114$ & $167 \pm 60$ & \\
Circularity & 3D & $0.78 \pm 0.05$ & $0.79 \pm 0.05$ & $0.76 \pm 0.06$ \\
& Section & $0.72 \pm 0.09$ & $0.71 \pm 0.10$ & \\
Ratio & 3D & $0.75 \pm 0.12$ & $0.77 \pm 0.10$ & $0.72 \pm 0.13$ \\
& Section & $0.70 \pm 0.14$ & $0.69 \pm 0.14$ & \\
SF & 3D & $0.61 \pm 0.18$ & $0.63 \pm 0.19$ & $0.68 \pm 0.19$ \\
& Section & $0.68 \pm 0.18$ & $0.70 \pm 0.20$ & \\
\hline
\end{tabular}

where $\sigma_{C}, \sigma_{E}, \sigma_{T}$ are errors due to corrosion, erosion and erosion-corrosion respectively. From the equation, it can be seen that, in order to obtain reliable data for synergy calculations, accurate measurements of all three components are required. Even the slightest skew in measurement can affect synergy calculations and propagate to significant error levels.

The materials selected for this work are stainless steel (SS316L), carbon steel (AISI 1020) and nickel-aluminium bronze (NAB). SS316L is widely used in the oil and gas industry, chemical plants and power plants and is known for its superior corrosion performance owing to its passivity. The presence of chromium in SS316L allows the formation of a thin layer of chromium oxide film that inhibits corrosion [23]. AISI 1020 however, is not as corrosion resistant as stainless steel and corrodes in atmospheric conditions where the relative humidity exceeds $60 \%$. However it is widely used in many engineering applications due to economical reasons. NAB on the other hand is widely used for propulsion and seawater handling systems in naval platforms and similar to SS316L also inhibits corrosion through the formation of a thick adherent oxide film. These three materials were tested to determine synergy levels and their resistance to the combined action of erosion and corrosion. Wear mechanisms were investigated for these material to develop a mechanistic understanding on erosion-corrosion.

\section{Experimental}

\subsection{Materials}

The materials tested in this work are stainless steel (SS316L), carbon steel (AISI 1020) and NAB with a hardness of $220 \mathrm{HV}_{(0.1)}$, $254 \mathrm{HV}_{(0.1)}, 235 \mathrm{HV}_{(0.1)}$ respectively. The chemical compositions of the materials tested are given in Table 1 . The test samples were cylindrical in shape with dimensions of $5 \mathrm{~mm}$ diameter and $70 \mathrm{~mm}$ length and were tested as received. The average surface roughness of the test samples is given in Table 2. Erodents used in the erosion and erosion-corrosion experiments are natural uncrushed silica sand. Table 3 summarises the average size of the sand used for testing. Optical analysis of the sand was performed by National Physical Laboratories (NPL) [24]. The hardness of the sand used was

Table 1

Chemical composition of materials used in the experiment (wt.\%).

\begin{tabular}{|c|c|c|c|c|c|c|c|c|c|c|c|}
\hline & $\mathrm{P}$ & $\mathrm{S}$ & Mn & $\mathrm{Al}$ & $\mathrm{Ni}$ & $\mathrm{Fe}$ & $\mathrm{Cr}$ & Mo & $\mathrm{Si}$ & $\mathrm{C}$ & $\mathrm{Cu}$ \\
\hline SS316L (UNS S31603) & 0.034 & 0.027 & 1.39 & - & 10.5 & Bal & 16.7 & 2.04 & 0.35 & 0.015 & - \\
\hline AISI 1020 (UNS G10200) & 0.05 & 0.05 & 0.6 & - & - & Bal & - & - & 0.35 & 0.25 & - \\
\hline NAB (UNS C63200) & - & - & 1.10 & 9 & 5 & 4.5 & 0.01 & - & - & - & Bal \\
\hline
\end{tabular}




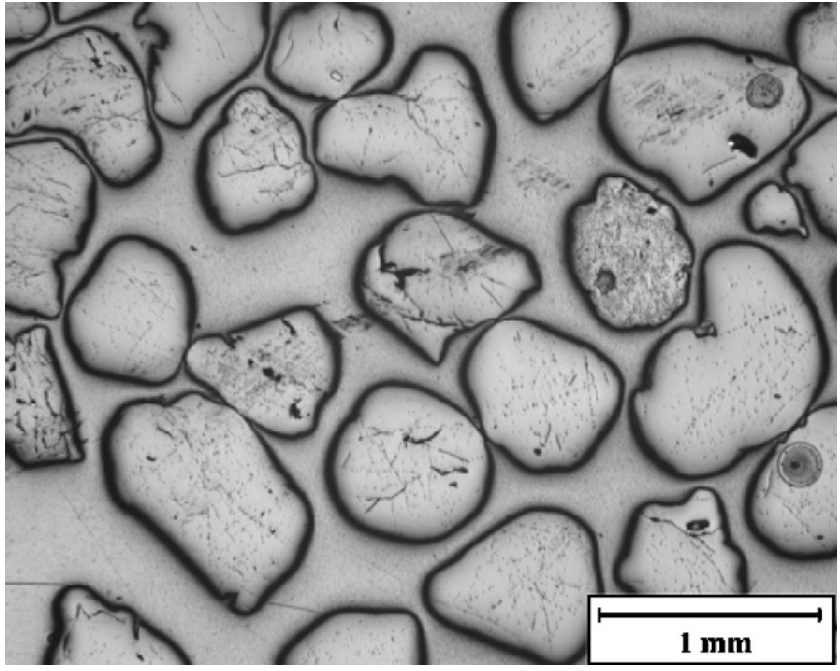

Fig. 1. Optical image of silica sand [24].

measured as $1100 \mathrm{HV}_{(0.3)}$. An optical cross-section image of the sand is shown in Fig. 1.

\subsection{Experimental rig}

A slurry pot erosion tester was used to perform erosioncorrosion experiments. Fig. 2 shows the diagram of the assembled slurry pot enclosed in the Faraday cage. Details of this experimental rig have been described elsewhere [4]. The rig is driven by a $3.5 \mathrm{~kW}$ motor which is connected to the slurry shaft through a toothed belt and two pulleys (on the shaft and on the motor). Cylindrical test samples are inserted between two nylon-coated arms at the end of the shaft as shown in Fig. 3 [4]. The speed of the motor is controlled through a variable speed drive with maximum rotation speed of up to $3500 \mathrm{rpm}\left(18.7 \mathrm{~m} \mathrm{~s}^{-1}\right)$. The pot is made of uPVC with a maximum capacity of 4 litres and has a cup type design copper cooler which allows the temperature of the slurry to be controlled by the circulation of hot/cold water. The pot is designed with baffles in it, to allow mixing of solid particles in the slurry, preventing it from settling at the bottom of the pot. The rig assembly is enclosed within a Faraday cage which allows electrochemical measurements to be made and also acts as a protective safety barrier when running experiments.

\subsection{Methodology}

In order to evaluate the pure erosion $(E)$, flow corrosion $(C)$ and erosion-corrosion $(T)$ rates at different test conditions, experiments

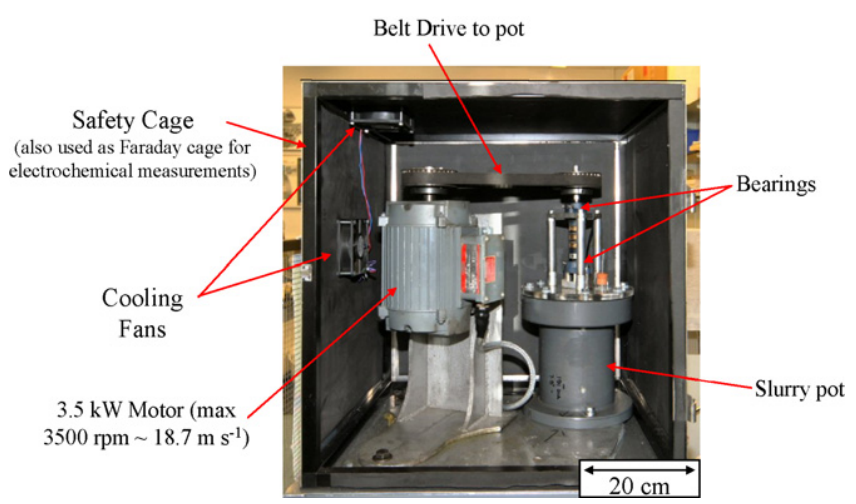

Fig. 2. Assembled slurry pot erosion tester enclosed in a Faraday cage (pot capacity 41) [4].

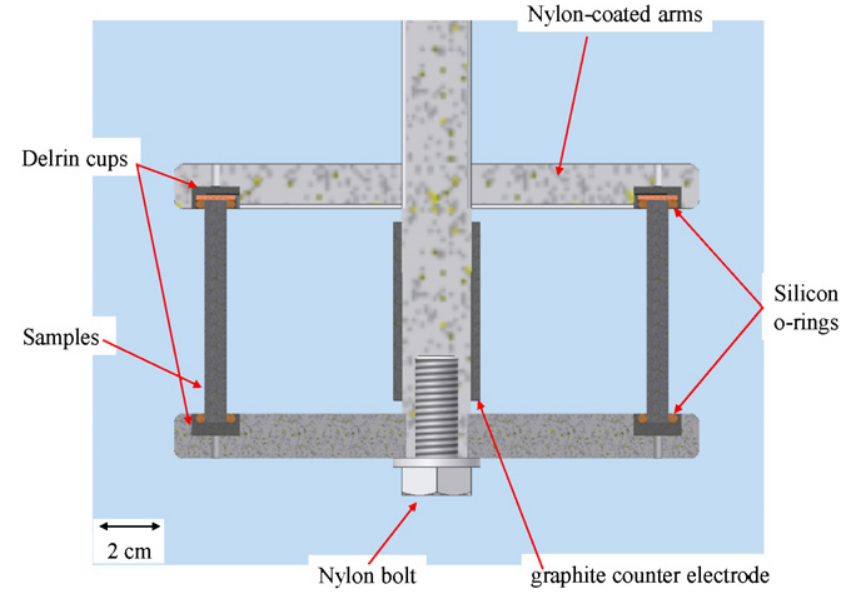

Fig. 3. Placement of samples on two nylon-coated arms, secured with o-rings to prevent slurry ingress [4].

were conducted in different test solutions. For the pure erosion experiments, $0.1 \mathrm{M} \mathrm{NaOH}$ was used as the test solution with the addition of silica sand. The pure corrosion experiments were performed using $3.5 \% \mathrm{NaCl}$ for AISI 1020 and $\mathrm{NAB}$ while $0.3 \mathrm{M} \mathrm{HCl}$ was used for SS316L. Erosion-corrosion experiments were performed using similar corrosive solutions as used in the pure corrosion experiments with the addition of silica sand. A variety of test solutions were evaluated to obtain positive synergy which included a range of $\mathrm{HCl}$ solution with different molarity, from $0.1 \mathrm{M} \mathrm{HCl}$ to $0.5 \mathrm{M} \mathrm{HCl}$. The rationale behind the choice of the test solutions for each material will be discussed in detail in Section 3.2. The temperature of the test solutions was maintained at $40 \pm 1{ }^{\circ} \mathrm{C}$ throughout the duration of the experiment. Tests were conducted at different velocities, sand sizes and sand concentrations to study the effect of the respective parameters on erosion-corrosion. Tables 4-6 shows the test matrix of the experiments conducted for the materials. To allow a manageable test programme, a complete test matrix was conducted for AISI 1020 while SS316L was tested at selected mid range values to compare its erosion-corrosion performance against AISI 1020. NAB was tested at one test condition in order to evaluate synergy values for different materials. The weight of the test samples was measured before and after the experiments to determine the mass loss for the different test conditions. Samples were cleaned in an ultrasonic bath and dried in a dessicator before gravimetric mass loss measurements were made. Gravimetric measurements were performed using a precision balance with an accuracy of $\pm 0.01 \mathrm{mg}$. Measurements were repeated six times for each sample and the maximum and minimum values were discarded. The remaining 4 readings were averaged to obtain an average mass loss for each test sample. As the rig design allows two samples to be used in a test, the average mass loss is taken between the two samples as the effective mass loss rate in $\mathrm{mg} \mathrm{h}^{-1}$.

\section{Results and discussion}

\subsection{Error analysis}

In order to determine the repeatability and to evaluate the experimental error in the experiments, a variation of replicated gravimetric measurements were performed on a single sample. Six gravimetric measurements were performed for each sample and the standard deviation was calculated for each set of measurements. Using the standard deviation data, a population graph was produced by sorting each standard deviation data in bins as shown in Fig. 4 . The average of the measurements $(0.046 \mathrm{mg})$ lies towards the right hand side of the population peak indicating that the data 
Table 4

Test matrix for AISI 1020

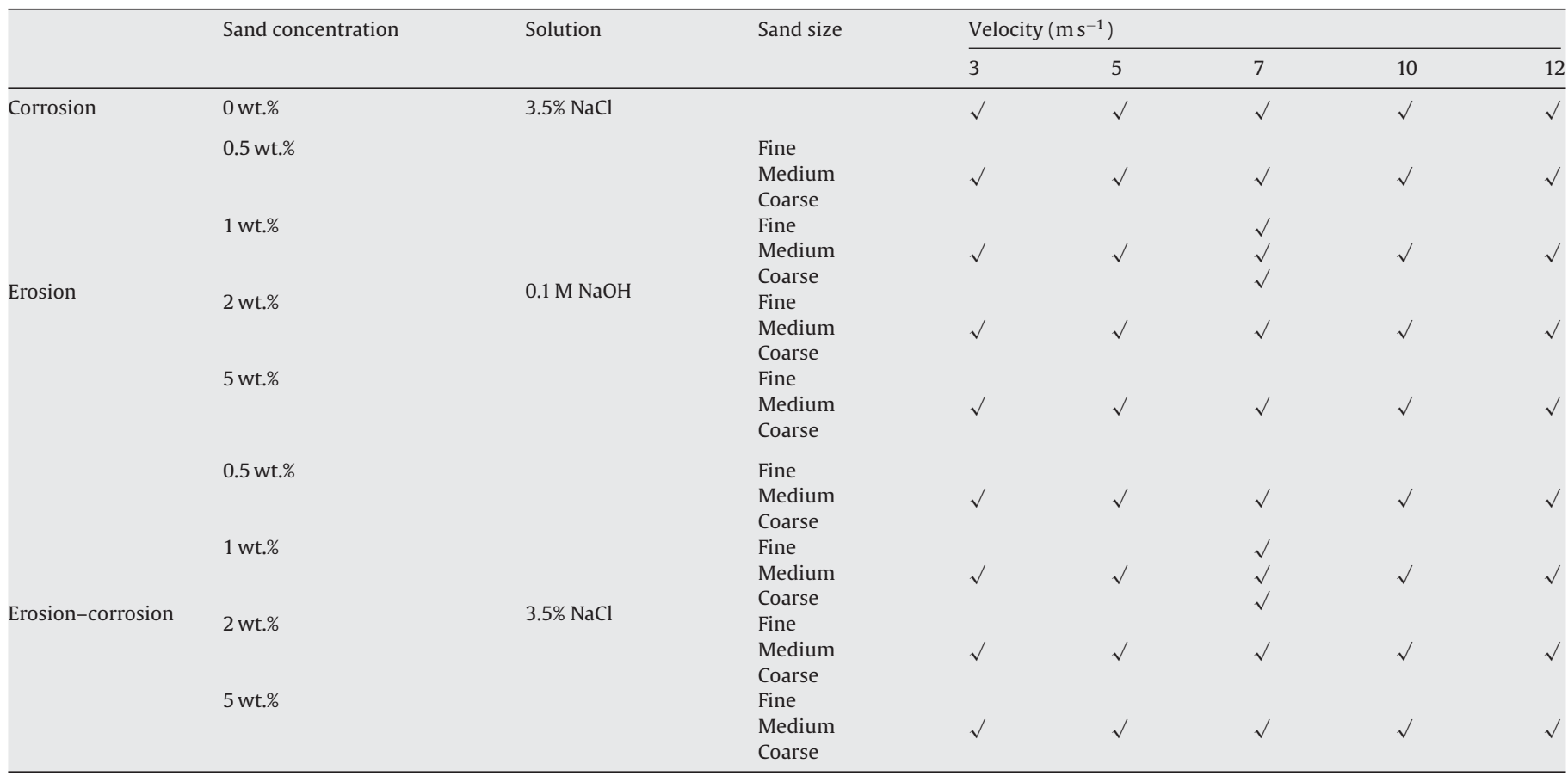

Table 5

Test matrix for SS316L

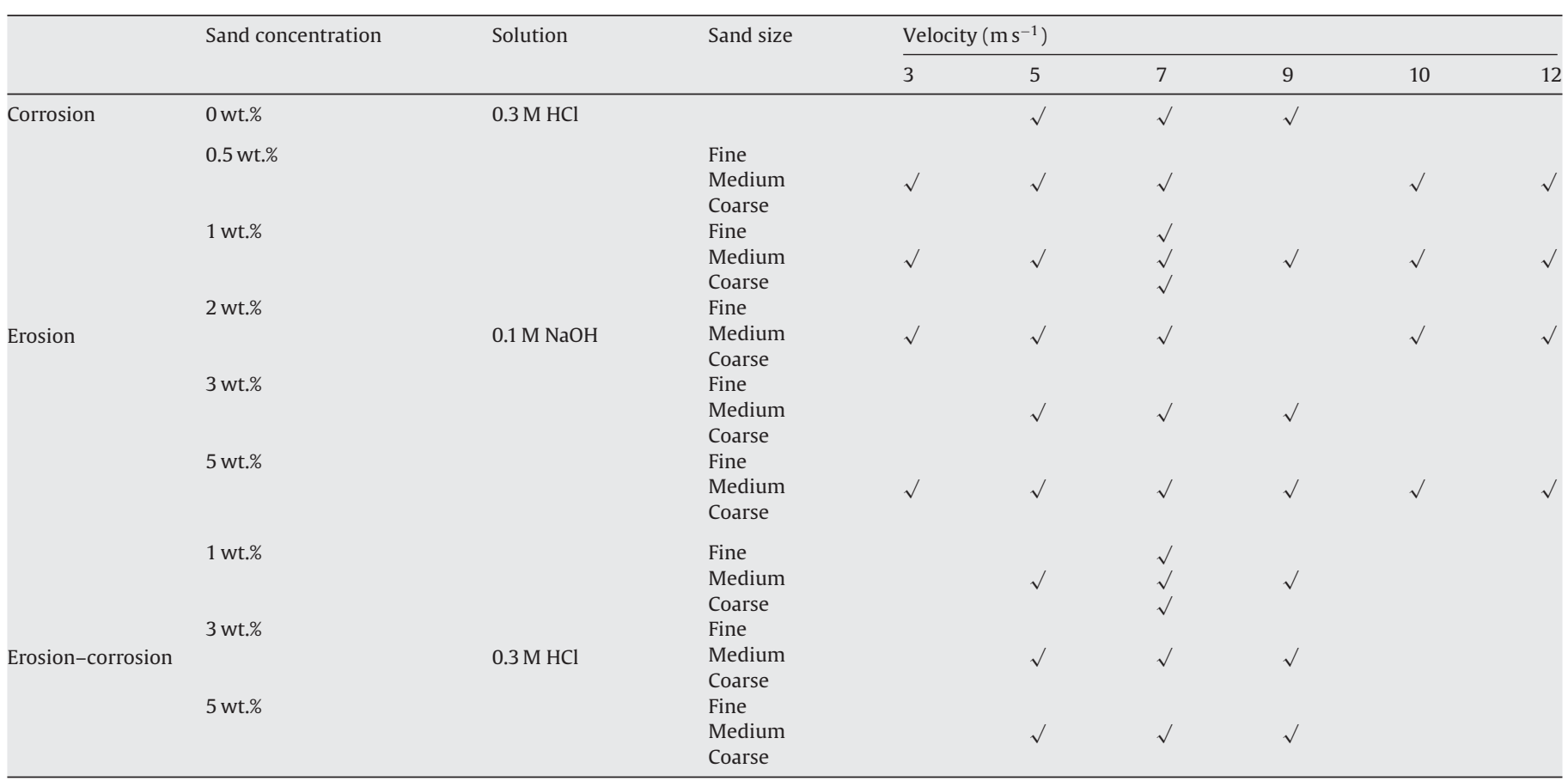

Table 6

Test matrix for NAB.

\begin{tabular}{|c|c|c|c|c|c|c|}
\hline & \multirow[t]{2}{*}{ Sand concentration } & \multirow[t]{2}{*}{ Solution } & \multirow[t]{2}{*}{ Sand size } & \multicolumn{3}{|c|}{ Velocity $\left(\mathrm{m} \mathrm{s}^{-1}\right)$} \\
\hline & & & & 5 & 7 & 9 \\
\hline Corrosion & 0wt.\% & $3.5 \% \mathrm{NaCl}$ & & & $\sqrt{ }$ & \\
\hline Erosion & 1 wt.\% & $0.1 \mathrm{M} \mathrm{NaOH}$ & $\begin{array}{l}\text { Fine } \\
\text { Medium } \\
\text { Coarse }\end{array}$ & & $\sqrt{ }$ & \\
\hline Erosion-corrosion & 1 wt.\% & $3.5 \% \mathrm{NaCl}$ & $\begin{array}{l}\text { Fine } \\
\text { Medium } \\
\text { Coarse }\end{array}$ & & $\sqrt{ }$ & \\
\hline
\end{tabular}


Table 7

Compilation of mass loss rate, error and confidence level (CL) obtained from the various test time durations for different erosion-corrosion tests.

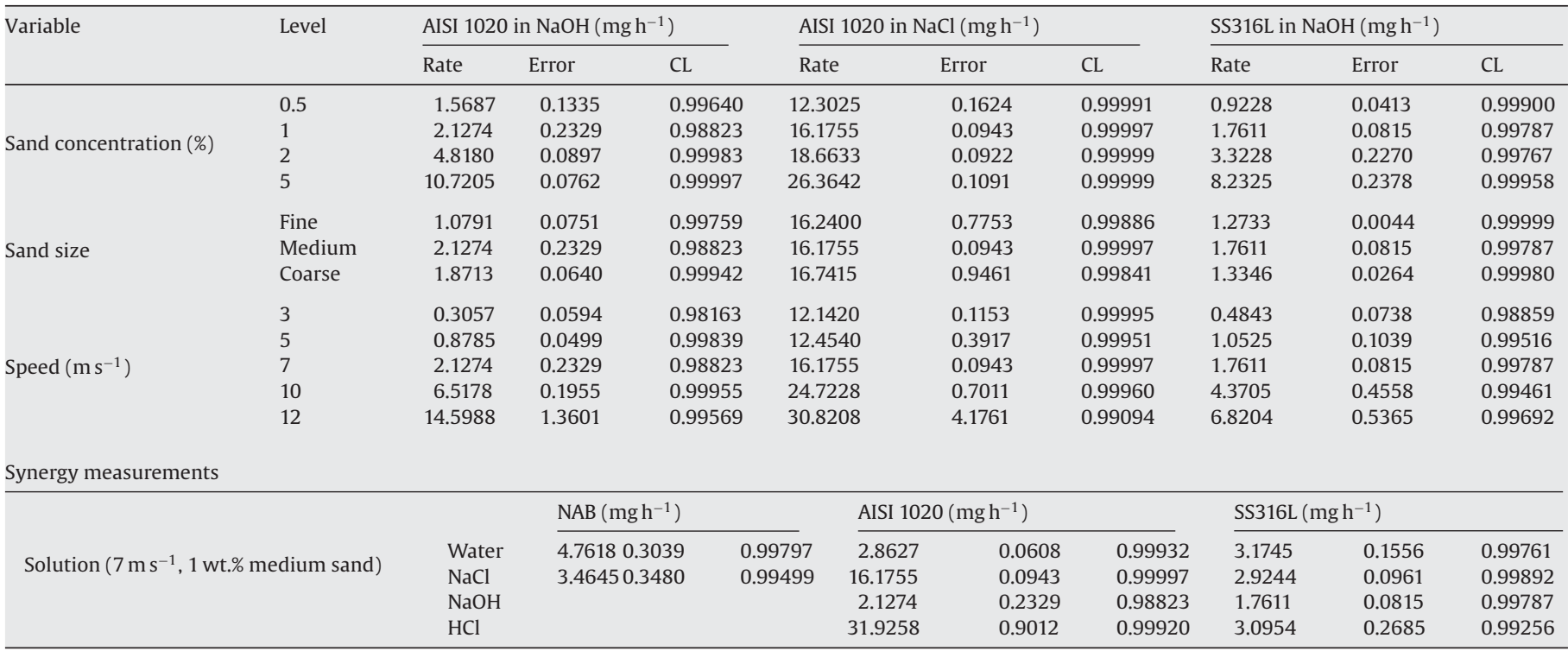

is skewed towards low error points. This shows that the gravimetric techniques adopted for measurements in these experiments have minimal high error values. To determine the mass loss rates, multiple tests were performed for a single test parameter at different durations. The reason for this is to determine the average mass loss rate in $\mathrm{mg} \mathrm{h}^{-1}$ and its relationship with increasing duration. In the current work, a linear relationship is observed for the mass loss with increasing duration (see Fig. 5). The slope of the linear fit provides the mass loss rate value at a given duration while the error is obtained from the slope. A confidence level is produced to provide information on the linearity as well as the overall error. A value closer to unity for the linear fit indicates better linearity and lower error between the mass loss with test duration. Table 7 tabulates the mass loss rate, error and confidence level obtained from the various test durations.

The calculated confidence level was extracted and sorted into a population graph as shown in Fig. 6. The average confidence level was determined to be 0.9972 , and most of the data fell above 0.994 , providing confidence in the linear relationship of mass loss rate. This is also reinforced by the count of percentage error shown

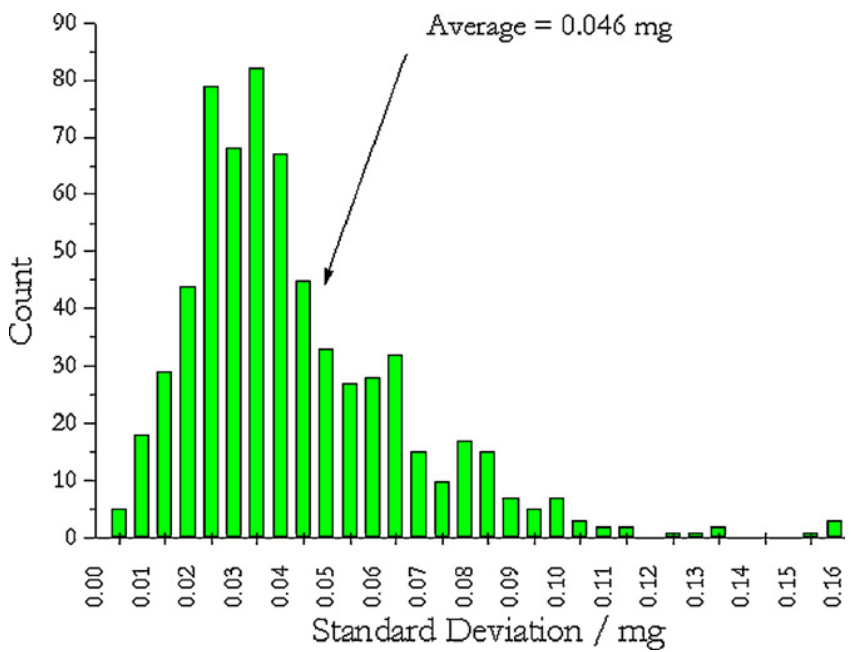

Fig.4. Population graph of gravimetric measurements standard deviation with average.

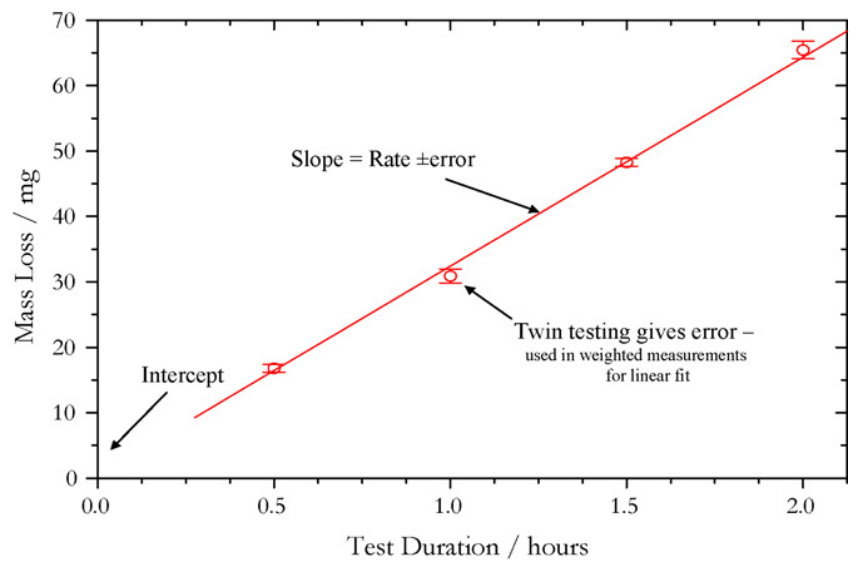

Fig. 5. Mass loss rate relationship with increasing time duration.

in Fig. 7 that demonstrates the experiments conducted have an error rate of less than $10 \%$ with an average of $5.5 \%$, only three values recorded errors of more than $10 \%$. The low relative errors in the experiments also provide confidence on the reproducibility of

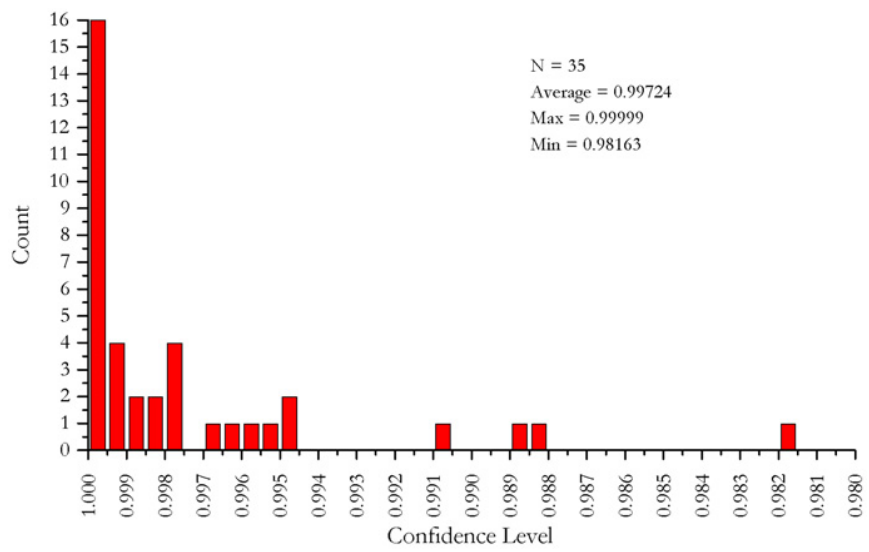

Fig. 6. Population graph of confidence level with average, maximum (max), minimum ( $\mathrm{min})$ and overall number $(N)$ 


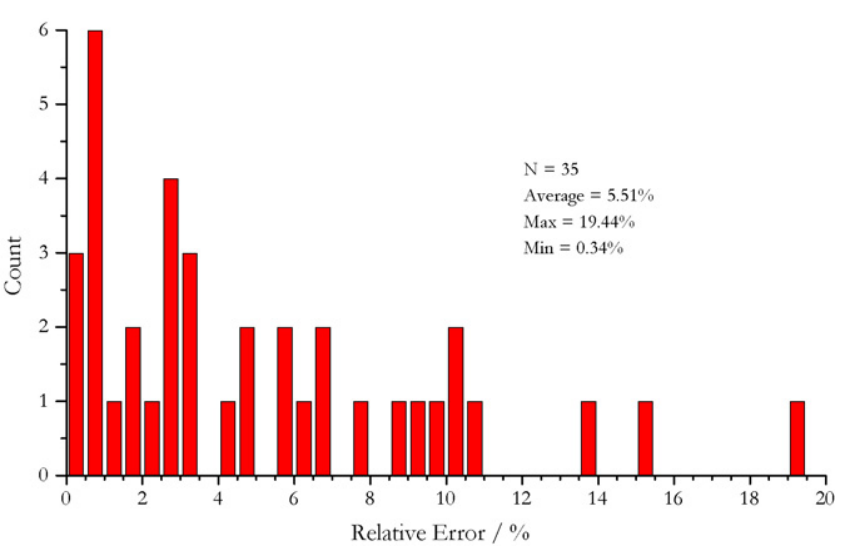

Fig. 7. Population graph of relative error of mass loss rate with average, maximum (max), minimum (min) and overall number $(N)$.

the experimental data. The relative errors for the mass loss rate obtained from the experiments were analyzed further to investigate the error distribution and Fig. 8 shows the error variation with increasing mass loss rate. The majority of the high relative errors occurred during the measurement of low mass loss rates. This trend is not surprising since at lower mass loss rates, the small differences in the samples before and after testing would influence the error in weighing the samples.

\subsection{Test solutions}

In order to ascertain the behaviour of the materials in an erosion dominated (passive) condition and a corrosion dominated (active) condition, a range of test solutions were used on SS316L and AISI 1020 to decide the best test solution for this work. The solutions tested were from a wide range of $\mathrm{pH}$ values including acidic $-\mathrm{pH}$ $1(0.1 \mathrm{M} \mathrm{HCl})$, neutral $-\mathrm{pH} 7$ (distilled water) and alkali $-\mathrm{pH} 14$ $(0.1 \mathrm{M} \mathrm{NaOH})$. In order to simulate seawater conditions $3.5 \% \mathrm{NaCl}$ was also used. Besides deciding on a suitable test solution for erosion and erosion-corrosion conditions, this part of the work also aims to look at synergy encountered by these materials and identify a test solution that would produce positive synergy, which is of primary interest to researchers in the field of erosion-corrosion. Fig. 9 shows the results of the erosion and erosion-corrosion experiments conducted with the various test solutions. AISI 1020 exhibited relatively low mass loss rates in $0.1 \mathrm{M} \mathrm{NaOH}$ and distilled water while it actively corroded in $3.5 \% \mathrm{NaCl}$ and $0.1 \mathrm{M} \mathrm{HCl}$. SS316L in contrast exhibited passivity in all test solutions with low mass loss rates. This shows that SS316L has good corrosion resistance to all the test solu-

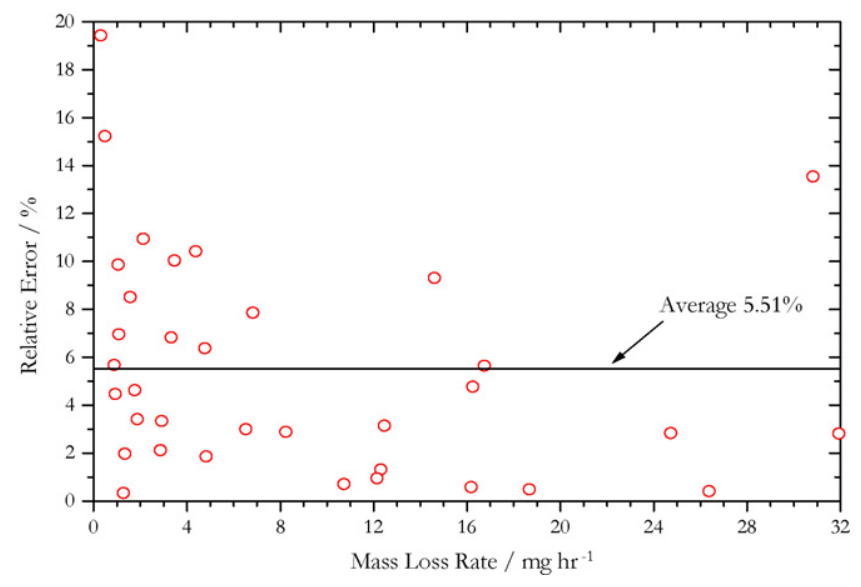

Fig. 8. Distribution of percentage error with increasing mass loss rate.

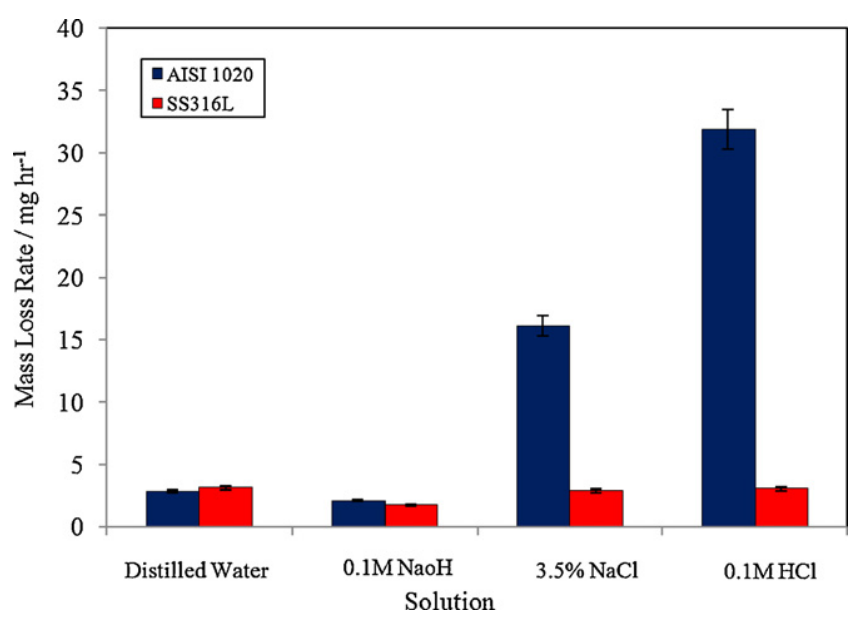

Fig. 9. Comparison of erosion and erosion-corrosion rates in different test solutions for SS316L and AISI 1020 ( $7 \mathrm{~m} \mathrm{~s}^{-1}, 1 \%$ sand concentration, medium sand).

tions, attributed to the chromium oxide film layer that minimizes charge transfer to and from the material. In order to obtain positive synergy and to assess the erosion-corrosion performance of SS316L, the range of test solutions were extended by increasing the molarity of $\mathrm{HCl}$ to $0.3 \mathrm{M}$ and $0.5 \mathrm{M}$. It has been shown that the passive film of SS316 $\mathrm{L}$ becomes unstable in $\mathrm{HCl}$ due to the aggressive chloride ions acting on the film [25]. Fig. 10 shows the mass loss variation with increasing $\mathrm{HCl}$ concentration, it was observed that even an increase to $0.3 \mathrm{M} \mathrm{HCl}$, the passivity of the chromium oxide film becomes unstable in erosion-corrosion conditions leading to an increased mass loss rate. The mass loss rate becomes more significant at $0.5 \mathrm{M}$ $\mathrm{HCl}$. From these initial tests, an informed decision was made on the choice of test solution for erosion and erosion-corrosion conditions for both materials. $0.1 \mathrm{M} \mathrm{NaOH}$ was chosen as the test solution for erosion experiments as it exhibited the most passive behaviour for both materials. 3.5\% $\mathrm{NaCl}$ was chosen as the test solution for AISI 1020 in erosion-corrosion conditions while $0.3 \mathrm{M} \mathrm{HCl}$ was chosen for SS316L. The choice of test solutions was based on the criteria for assessing positive synergy on both materials which will be discussed further in Section 3.6. The second criterion for the choice of the test solution was based on the aggresivity of the test solution towards the test rig which eliminated $0.5 \mathrm{M} \mathrm{HCl}$ from further consideration in the current work.

The effect of increasing the sand concentration on erosion and erosion-corrosion is depicted in Fig. 11. A similar relationship is observed in all four test conditions where the increase

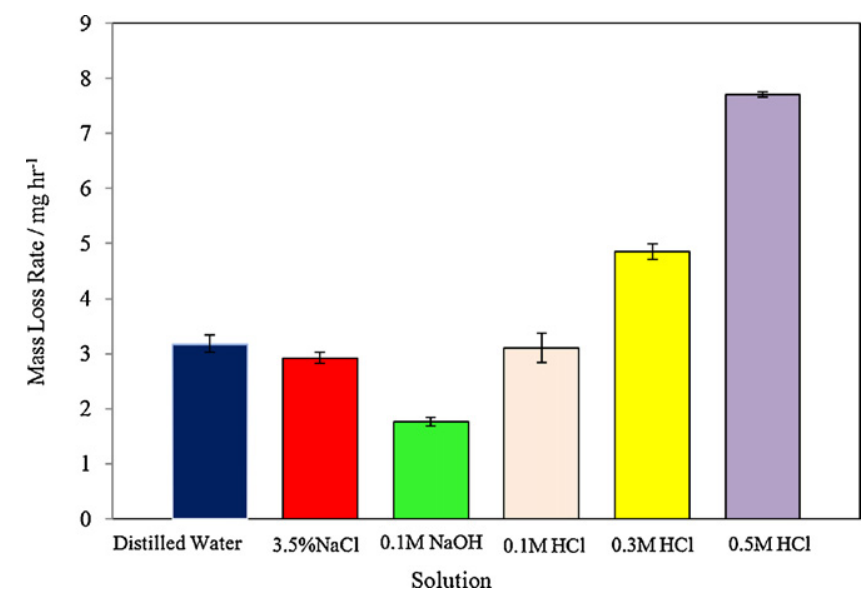

Fig. 10. Evaluation of mass loss for SS316L in various test solutions $\left(7 \mathrm{~m} \mathrm{~s}^{-1}, 1 \%\right.$ sand concentration, medium sand $(294 \mu \mathrm{m}))$. 


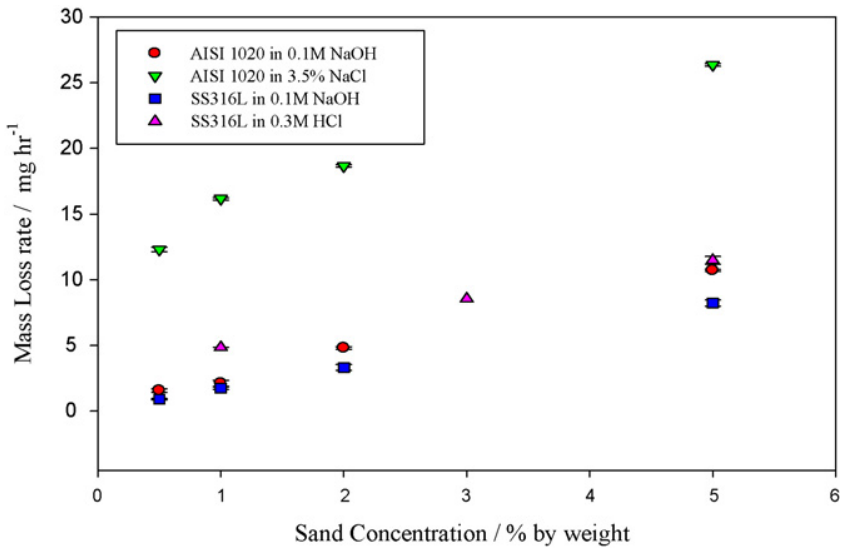

Fig. 11. Mass loss rate with sand concentration variation $\left(7 \mathrm{~m} \mathrm{~s}^{-1}\right.$, medium sand).

in sand concentration results in an increase in the erosion and erosion-corrosion mass loss rate for SS316L and AISI 1020. For both metals, the erosion mass loss rate increased with sand concentration but was lower than the erosion-corrosion mass loss rate. AISI 1020 exhibited a significantly higher mass loss rate compared to SS316L during erosion-corrosion conditions which is expected for a less noble metal. The erosion rate is known to increase with sand concentration because of the increase in the number of particles impacting the surface causing material loss [26]. However, this relationship is not that simple as it has also been seen that the increase in sand concentration can lead to a decrease in erosion rate attributed to the rebounding of the particles near the surface of the material, protecting the surface from subsequent impacts [27]. No such effect was observed in this work possibly due to the low sand concentrations (up to 5\%) used in this experiment where the "screening" effect is not observed. The higher increase in mass loss rate with sand concentration for both materials in erosion-corrosion conditions on the other hand is believed to be due to the contribution of corrosion in accelerating the wear rate. SS316L exhibits a lower mass loss rate as compared to AISI 1020 due to the ability of SS316L to form a chromium oxide rich passive film which inhibits corrosion. Although the rate of removal of the passive film for SS316L is dependent on the percentage of solids [28], the low erosion-corrosion rates show that the passive film is fast reforming in this material. More recent studies by $\mathrm{Hu}$ and Neville [29] identified a critical solid loading above which the depassivation-repassivation process becomes critical for a passive metal as it results in a higher charge transfer from the material associated with increasing particle impacts. This finding is considered important for passive metals as it proves that there is an upper and lower threshold for erosion-corrosion wear rate. When the sand concentration is lower than the critical limit, the effective removal of the passive film to accelerate mass transfer is minimal, similarly above the critical sand concentration particle rebounding prevents effective material removal to occur as it prevents incoming particles from impacting the surface.

\subsection{Velocity variation}

As the velocity increases, the erosion and erosion-corrosion rates is found to increase for AISI 1020 and SS316L (see Fig. 12). However at low speeds of $3 \mathrm{~m} \mathrm{~s}^{-1}$ and $5 \mathrm{~m} \mathrm{~s}^{-1}$ the mass loss difference between both velocities is minimal. This can be explained by the flow field effect in the slurry pot. At low velocities, the erodents are not completely suspended in the fluid therefore effective erosion is unable to take place. A higher increase in mass loss rate with velocity variation for erosion-corrosion conditions is observed compared to pure erosion conditions with AISI 1020 having higher

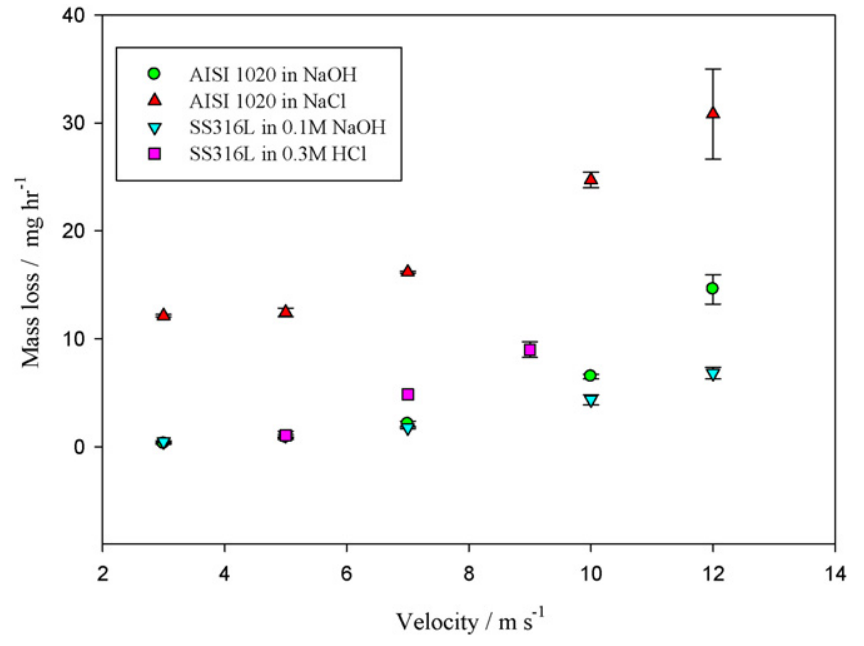

Fig. 12. Mass loss rate with linear velocity variation ( $1 \%$ sand concentration, medium sand $(294 \mu \mathrm{m}))$.

mass loss rates than SS316L in both conditions. It is known that the velocity exponent for the erosion rate increases to the power of between 2 and 3 for ductile material [30]. In the current work, the velocity exponent for AISI 1020 and SS316L in pure erosion conditions was evaluated to be 2.7 and 2.1 respectively, values consistent for ductile metals. This relationship is more complex for erosion-corrosion due to the presence of the additional corrosion effect which also varies with velocity. For pure erosion, the increase in erosion rate with velocity is associated with the increase in kinetic energy of the erodents causing more effective damage on the metal surface. For corrosion, the increase in velocity increases the effective mass transfer between the metal and corrosive fluid hence accelerating the electrochemical process of corrosion. AISI 1020 , which is susceptible to corrosion, suffers severe mass loss in erosion-corrosion conditions due to the combined effect of velocity in both processes. For a passive metal like SS316L, the increase in velocity accelerates the mechanical removal rate of the passive film thus accelerating the overall erosion-corrosion process [28]. At the same time the increase in flow velocity can also accelerate the repassivation rate by increasing the supply of dissolved oxygen and chromium ions necessary to repair the chromium oxide film that has been destroyed by solid particle impingement [31]. The rate of depassivation and repassivation then becomes critical in enhancing or suppressing the total erosion-corrosion rate for SS316L.

\subsection{Sand size variation}

One of the many factors that affect erosion and erosioncorrosion rates is the particle size. Fig. 13 shows the variation of mass loss rate with particle size. Tests conducted on both erosion and erosion-corrosion for SS316L and AISI 1020 showed that medium sand produced the highest mass loss rate followed by coarse sand with the lowest rates seen for tests with fine sand conditions. This finding is rather interesting as it implies that there exists an optimal particle size range in a slurry pot erosion tester that causes maximum erosion and erosion-corrosion which lies between $100 \mu \mathrm{m}$ and $600 \mu \mathrm{m}$. The concept of collision efficiency defined as the ratio of the number of particles striking the surface and the number of particles contained within the volume of suspension swept by that area in unit time is a useful parameter in examining the particle size effect in erosion process [32]. Smaller particles are said to suffer from particle retardation prior to impact resulting lower collision efficiency of the particles. This will lead to a lower dissipation of kinetic energy at impact and decrease the ero- 


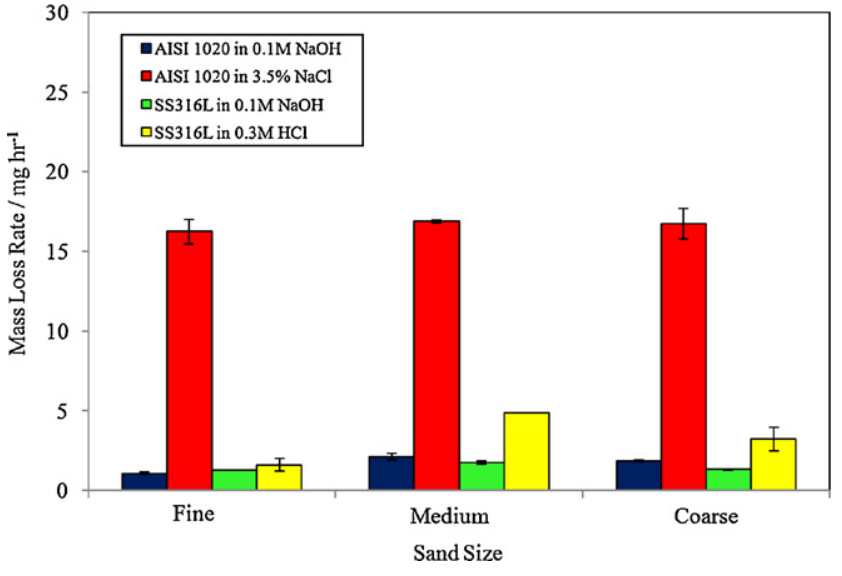

Fig. 13. Mass loss rate with sand size variation ( $7 \mathrm{~m} / \mathrm{s}, 1 \%$ sand concentration).

sion rate. It was also noted that for particles less than $100 \mu \mathrm{m}$, the particles might fail to rebound from the surface due to the squeeze film effect and at smaller sizes they might even fail to penetrate the squeeze film and impact the surface [7]. However, as the particles become larger, the possibility of particles rebounding and impacting incoming particles might also increase similar to the effect of increasing the sand concentration which causes the "screening" effect. This provides a possible explanation on the optimal sand size for maximum erosion. The threshold for particle size effect is also similar for erosion-corrosion where the increase in particle size leads to an increase in the erosion-corrosion rate but above a critical value, the erosion-corrosion rate is independent of particle size [20].

\subsection{Erosion-corrosion mechanisms}

Fig. 14 shows the SEM micrographs taken for erosion-corrosion experiments at $7 \mathrm{~m} \mathrm{~s}^{-1}, 1 \%$ sand concentration and medium sand size $(294 \mu \mathrm{m})$ for SS316L, AISI 1020 and NAB. The SEM micrographs for SS316L (Fig. 14(a) and (b)) and NAB (Fig. 14(e) and (f)) shows surface roughening with the formation of multiple superimposed craters and platelets as the main mechanism for erosion-corrosion, indicating these two materials undergo multiple impacts leading to the formation of vulnerable lips that can be removed by subsequent impacts. The SEM micrographs show similar mechanisms to the cutting mechanism proposed by Hutchings where the type of cut-
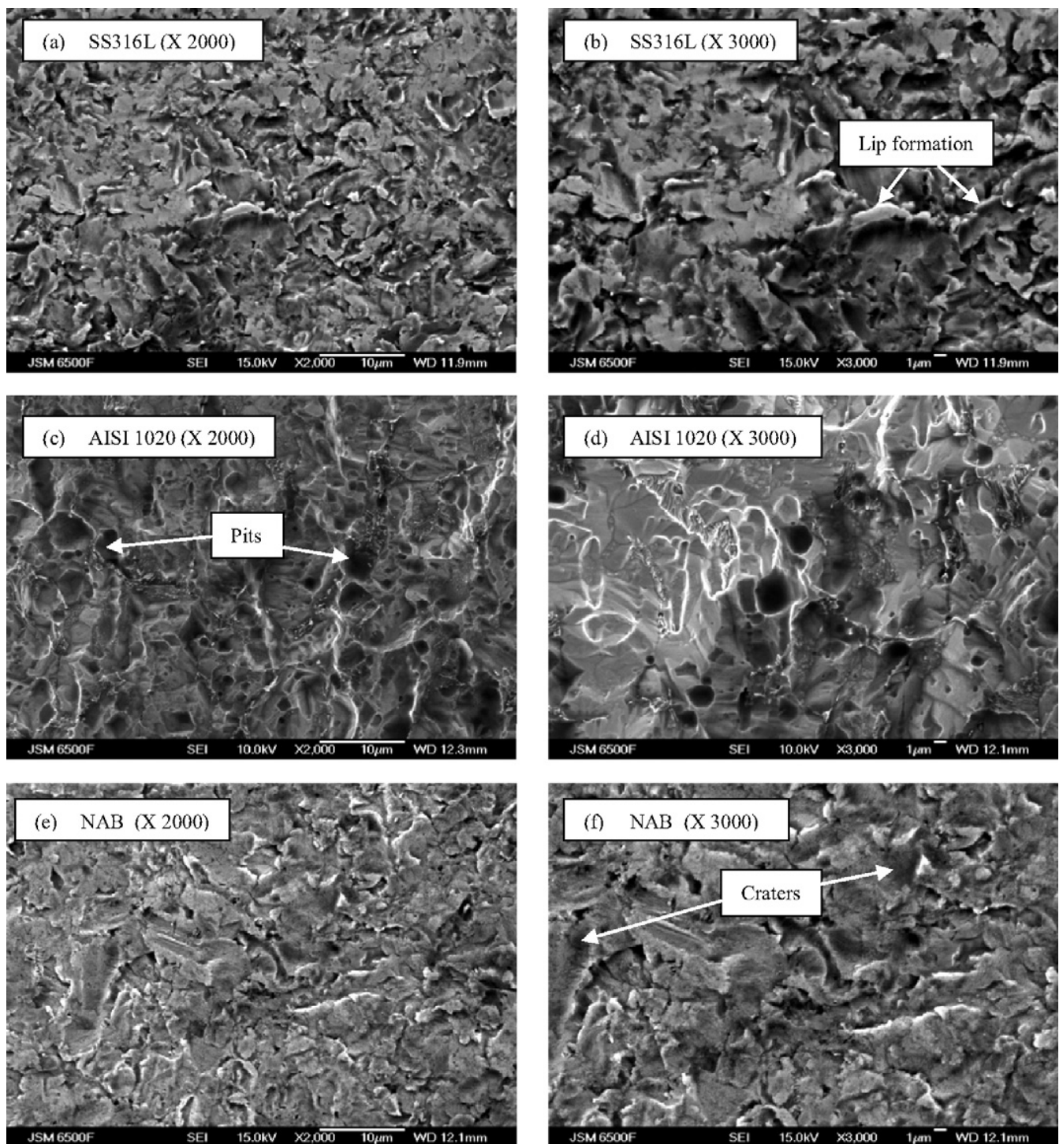

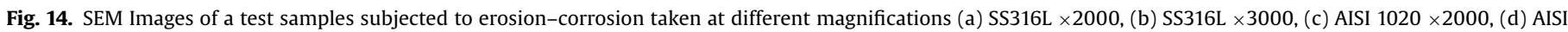
$1020 \times 3000$, (e) NAB $\times 2000$, (f) NAB $\times 3000$ (test conditions: velocity $7 \mathrm{~m} \mathrm{~s}^{-1}$, sand concentration $1 \%$, medium sand $(294 \mu \mathrm{m})$ ). 
ting depends on whether the particle rolls forward or backwards to remove the material from the surface [33]. It can be deduced that for SS316L and NAB, erosion dominated the overall erosion-corrosion process. For AISI 1020, shown in Fig. 14(c) and (d), the mechanism that occurs for erosion-corrosion is slightly different to SS316L and NAB. Although surface roughening due to particle impacts are still observed, the formation of lips and platelets are minimal and in contrast the surface shows formation of craters, indentations and pits. One possible explanation for this is that for AISI 1020 under erosion-corrosion conditions, electrochemical corrosion plays a dominant role in material removal by attacking the weakened layer of the eroded section causing material removal, exposing the indented area. Subsequent corrosion attack on this indented area causes the formation of corrosion pits. The lips which were formed could have also been removed by the initiation of cracks at the root of the distressed lips due to corrosion attack which is vulnerable to material removal [1]. From the SEM micrographs a clear distinction can be made on the erosion-corrosion mechanisms for an erosion dominated material (SS316L and NAB) and a corrosion dominated material (AISI 1020).

\subsection{Synergy}

AISI 1020 exhibited negative synergy in $0.1 \mathrm{M} \mathrm{NaOH}$ and $0.1 \mathrm{M}$ $\mathrm{HCl}$ and only exhibited positive synergy in $3.5 \% \mathrm{NaCl}$ as shown in Fig. 15. Although these results are expected for a passive solution like $0.1 \mathrm{M} \mathrm{NaOH}$, the existence of negative synergy in $0.1 \mathrm{M} \mathrm{HCl}$ is rather surprising since it is expected that in an aggressive acidic condition like $0.1 \mathrm{M} \mathrm{HCl}$, positive synergy would occur. Examining the synergy trends in SS316L, negative synergy was observed on all test solutions except $0.3 \mathrm{M} \mathrm{HCl}$ where a substantial increase of positive synergy was seen. In erosion-corrosion studies conducted by Matsumura et al. [25] with $5 \%$ hydrochloric acid, it was found that the chloride ions adsorbed on the surface for SS304 inhibited erosion-corrosion which explains the negative synergy behaviour on both materials at low concentrations of $\mathrm{HCl}$. The study further shows that on passive metals such as stainless steel, the rate of synergy is increased by the act of solid particles damaging the surface which increases the corrosion activity hence the synergism. An important finding from their studies is that the erosion-corrosion rates in a stable passive film environment (1\% sulphuric acid) are higher than those in an environment where the passive film is unstable (5\% hydrochloric acid) which shows that the passive film is not the only factor in determining the synergism of the material. $\mathrm{NAB}$ was only tested in $3.5 \% \mathrm{NaCl}$ and a high negative synergy of $-64 \%$ was observed. In the work conducted by Barik et al. [34] on

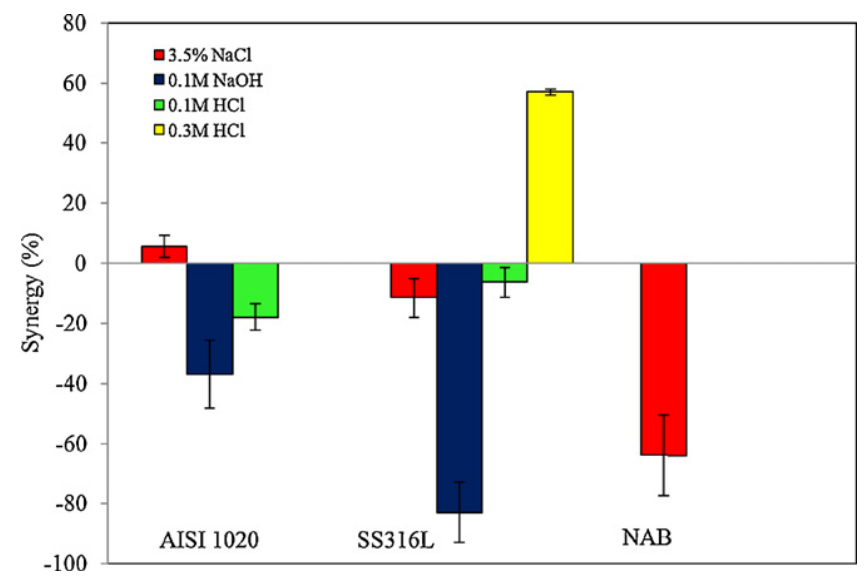

Fig. 15. Synergy measurements for the three material tested variation $\left(7 \mathrm{~m} \mathrm{~s}^{-1}, 1 \%\right.$ sand concentration, medium sand $(294 \mu \mathrm{m}))$.

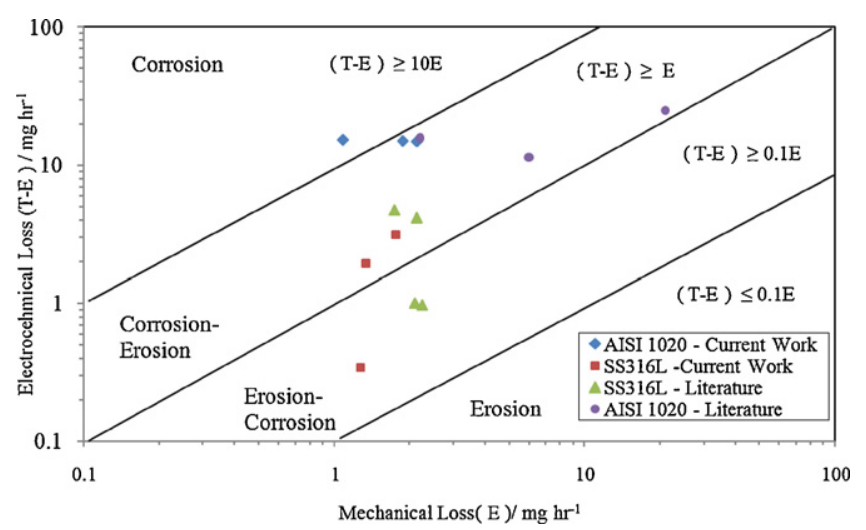

Fig. 16. Classification of materials tested by electrochemical loss $(T-E)$ versus mechanical loss $(E)$.

erosion-corrosion of cast NAB for velocities between $3.1 \mathrm{~m} \mathrm{~s}^{-1}$ and $6 \mathrm{~m} \mathrm{~s}^{-1}$, negative synergies of up to $-31.4 \%$ were observed inferring that $\mathrm{NAB}$ has good resistance under the combined action of erosion and corrosion. $\mathrm{NAB}$ forms a thick adherent oxide layer of cuprous oxide $\left(\mathrm{Cu}_{2} \mathrm{O}\right)$ and alumina $\left(\mathrm{Al}_{2} \mathrm{O}_{3}\right)$, which remains intact under solid particle impingement suppressing erosion-corrosion particularly at low kinetic energies.

Comparing all three test materials under erosion-corrosion conditions in $3.5 \% \mathrm{NaCl}, \mathrm{SS} 316 \mathrm{~L}$ is observed to have the lowest material loss with a mass loss rate of $2.9 \mathrm{mg} \mathrm{h}^{-1}$ followed by NAB (3.46 $\mathrm{mg} \mathrm{h}^{-1}$ ) and AISI 1020 (16.18 $\mathrm{mg} \mathrm{h}^{-1}$ ) (see Table 7). However, in terms of synergistic ranking, NAB is seen to have the highest negative synergy $(-63.9 \%)$ in erosion-corrosion conditions suggesting that this material has the best resistance to the combined action of erosion and corrosion followed by SS316L (-11.5\%) while AISI 1020 exhibited positive synergy $(5.5 \%)$ indicating that this materials suffers additional wear due to the interaction between erosion and corrosion. Looking at the SEM surface for AISI 1020 it could be deduced that corrosion attacks the distressed lips formed during erosion hence accelerating the total wear rate. The ranking provides useful information as it shows that a material that is erosion-corrosion resistant does not necessarily suffer from low synergy levels. Therefore careful judgement should be made when comparing material loss rate and synergy rates to make an informed decision on the most suitable material for a given application.

Another method for classifying erosion-corrosion data is by the plot of electrochemical loss $(T-E)$ versus mechanical loss (E) as shown in Fig. 16 for analyzing positive synergy [4]. In this map erosion-corrosion is divided into four regimes namely corrosion regime, erosion regime, erosion-corrosion regime and corrosion-erosion regime. The corrosion dominated region $(T-E \geq 10 E)$ indicates that the material losses due to electrochemical process is equal to or more than ten times the losses due to mechanical process and vice versa for the erosion dominated region. The effect of sand size variation is plotted on this graph. It can be seen that for AISI 1020, the mass loss rates fall between the corrosion and corrosion-erosion regime indicating that this material is dominated by active corrosion which is consistent for AISI 1020 which is susceptible to corrosion. However for SS316 $\mathrm{L}$ in $0.3 \mathrm{M} \mathrm{HCl}$ although still classified under the corrosion-erosion regime with one point lying on the erosion-corrosion regime, the influence on erosion and corrosion is seen as almost proportionate to each other exhibiting the passivity of the metal suffering corrosion when there are solid particles impinging on it. The experimental data from the current work was compared with data from published literature for erosion-corrosion of carbon steel [3] and stainless steel [28,35,36]. A common trend is indentified where the points for carbon steel in 
all cases exhibit higher electrochemical loss at almost similar rates, varying only in mechanical loss as the test conditions are changed. In contrast, points for SS316L vary vertically along the wear map indicating varying electrochemical loss with change in test conditions. A conclusion that can be made from this plot is that for a material that is corrosion dominated such as carbon steel, the corrosion rate is already high even without the presence of erosion therefore the electrochemical loss is not significant. The electrochemical loss of SS316L on the other hand varies significantly in the presence of erosion because the removal of the chromium oxide layer by solid particle impingement accelerates the corrosion rate substantially.

\section{Conclusions}

A set of erosion, corrosion and erosion-corrosion experiments were carried out to evaluate the repeatability of erosion-corrosion experiments and to investigate the role of different parameters influencing erosion-corrosion. Three test materials namely stainless steel 316L, carbon steel (AISI 1020) and NAB were tested to determine synergy levels in these materials and were ranked relative to its erosion-corrosion resistance. The following conclusions can be made from the current work:

1. The low error rates and the high confidence levels obtained from the experiments showed that the measurements and slurry pot erosion rig provide repeatable and reproducible test results. The error in calculation for erosion-corrosion rates was found to have an average of $5.5 \%$ and only a few more than $10 \%$.

2. AISI 1020 exhibited passive behaviour in $0.1 \mathrm{M} \mathrm{NaOH}$ and distilled water but was actively corroding in $3.5 \% \mathrm{NaCl}$ and $0.1 \mathrm{M}$ $\mathrm{HCl}$ with mass loss increase of between $14 \mathrm{mg} \mathrm{h}^{-1}$ and $30 \mathrm{mg} \mathrm{h}^{-1}$. SS316L in contrast, exhibited passivity in all test solutions with mass loss rates of less than $2 \mathrm{mg} \mathrm{h}^{-1}$. The test conditions were extended by increasing the molarity of $\mathrm{HCl}$ to study the effect of erosion-corrosion on SS316L. It was found that at $0.3 \mathrm{M} \mathrm{HCl}$ and $0.5 \mathrm{M} \mathrm{HCl}, \mathrm{SS} 316 \mathrm{~L}$ started producing positive synergy with mass loss rates of between $4.8 \mathrm{mg} \mathrm{h}^{-1}$ and $7.7 \mathrm{mg} \mathrm{h}^{-1}$.

3. Increasing the velocity and the sand concentration produced higher mass loss rates for AISI 1020 and SS316L. Mass loss increase of between $8 \mathrm{mgh}^{-1}$ and $18 \mathrm{mgh}^{-1}$ is seen for AISI 1020 and SS316L in erosion-corrosion conditions. The increase in kinetic energy of the particles is suggested to be the reason for the higher mass loss rates.

4. Medium sand $(294 \mu \mathrm{m})$ showed the highest mass loss rate followed by coarse sand and fine sand in erosion-corrosion conditions for both SS316L and AISI 1020. The difference in mass loss between medium sand and fine sand was found to be between $3.6 \mathrm{mg} \mathrm{h}^{-1}$ for SS316L and $0.6 \mathrm{mg} \mathrm{h}^{-1}$ for AISI 1020.

5. SEM micrographs showed that a similar erosion-corrosion mechanism is seen for SS316L and NAB with the formation of multiple extruded lips and platelets typically seen for erosion dominated materials. In contrast AISI 1020 surface revealed the formation of craters, pits and shallow indentations which suggests that the material is corrosion dominated. The surface features observed from SEM explains the reason why AISI 1020 suffered significantly higher mass loss rates, as corrosion was accelerating wear by attacking the distressed lips formed during particle erosion.

6. The additional wear rate due to the interaction between erosion and corrosion (synergy) was evaluated for SS316L, NAB and AISI 1020 in different test solutions and positive synergy of 5.5\% and $57 \%$ was evident for AISI 1020 in $3.5 \% \mathrm{NaCl}$ and SS316L in $0.3 \mathrm{M} \mathrm{HCl}$ respectively. NAB exhibited negative synergy $(-63.9 \%)$ in $3.5 \%$ $\mathrm{NaCl}$.
7. Comparing all three test materials under erosion-corrosion conditions in $3.5 \% \mathrm{NaCl}, \mathrm{SS} 316 \mathrm{~L}$ is seen to have the lowest material loss with a mass loss rate of $2.9 \mathrm{mg} \mathrm{h}^{-1}$ followed by NAB $\left(3.46 \mathrm{mg} \mathrm{h}^{-1}\right.$ ) and AISI $1020\left(16.18 \mathrm{mg} \mathrm{h}^{-1}\right)$. However in terms of synergistic ranking, NAB is seen to have the highest negative synergy $(-63.9 \%)$ in erosion-corrosion conditions suggesting that this material has the best resistance to the combined action of erosion and corrosion followed by SS316L $(-11.5 \%)$ while AISI 1020 exhibited positive synergy (5.5\%) indicating that this material suffers additional wear due to the interaction between erosion and corrosion.

\section{Acknowledgements}

This work was partly sponsored by National Physical Laboratories (NPL). The authors would like to thank Mark Gee and Andrew Gant (NPL) for supply of materials and technical help.

\section{References}

[1] Y. Li, G.T. Burstein, I.M. Hutchings, The influence on the erosion of aluminium by aqueous silica slurries, Wear 186-187 (1995) 515-522.

[2] R.J.K. Wood, S.P. Hutton, The synergistic effect of erosion-corrosion: trends in published results, Wear 140 (1990) 387-394.

[3] R.J.K.Wood, Erosion-corrosion synergism for multi-phase flowline materials, Proceedings of the 3rd International Conference on Cavitation, Inst. Mech. Eng, Cambridge, Paper C453/011, (1992), 151-158.

[4] T.J. Harvey, J.A. Wharton, R.J.K. Wood, Development of synergy model for erosion-corrosion of carbon steel in a slurry pot, Tribol. Mater. Surf. Interfaces 1 (1) (2007) 33-47.

[5] H.M. Clark, K.K. Wong, Impact angle, particle energy and mass loss in erosion by dilute slurries, Wear 186-187 (1995) 454-464.

[6] H.M. Clark, Particle velocity and size effects in laboratory slurry erosion measurements OR. . . Do you know what your particles are doing? Tribol. Int. (2002) 617-624.

[7] H.M. Clark, R.B. Hartwich, A re-examination of the 'particle size' effect in slurry erosion, Wear 248 (2001) 147-161.

[8] H.M. Clark, On the impact rate and impact energy of particles in a slurry pot erosion tester, Wear 147 (1991) 165-183.

[9] H.M. Clark, Specimen diameter, impact velocity, erosion rate and particle density in a slurry pot erosion tester, Wear 162-164 (1993) 669-678.

[10] J.B. Zu, I.M. Hutchings, G.T. Burstein, Design of a slurry erosion test rig, Wear 140 (1990) 331-344.

[11] R.J.K. Wood, J.A. Wharton, A.J. Speyer, K.S. Tan, Investigation of erosion-corrosion processes using electrochemical noise measurement, Tribol. Int. 35 (2002) 631-641.

[12] A.J. Speyer, Wear corrosion sensing in flowing seawater, Ph.D. Thesis, University of Southampton, 2002.

[13] K.S. Tan, J.A. Wharton, R.J.K. Wood, Solid particle erosion-corrosion behaviour of a novel HVOF nickel aluminium bronze coating for marine applications-correlation between mass loss and electrochemical measurements, Wear 258 (2005) 629-640.

[14] A. Neville, T. Hodgkiess, J.T. Dallas, A study of the erosion-corrosion behaviour of engineering steels for marine pumping applications, Wear 186-187 (1995) 497-507.

[15] H.M. Clark, H.M. Hawthorne, Y. Xie, Wear rates and specific energies of some ceramic, cermet and metallic coatings determined in the Coriolis erosion tester, Wear 233-235 (1999) 319-327.

[16] H.M. Clark, J. Tuzson, K.K. Wong, Measurements of specific energies for erosive wear using a Coriolis erosion tester, Wear 241 (2000) 1-9.

[17] Y. Xie, H.M. Clark, H.M. Hawthorne, Modelling slurry particle dynamics in the Coriolis erosion tester, Wear 225-229 (1999) 405-416.

[18] R.J.K. Wood, T.F. Jones, Investigations of sand-water induced erosive wear of AISI 304L stainless steel pipes by pilot-scale and laboratory-scale testing, Wear 255 (2003) 206-218.

[19] R.J.K. Wood, T.F. Jones, J. Ganeshalingam, N.J. Miles, Comparison of predicted and experimental erosion estimates in slurry ducts, Wear 256 (2004) 937-947.

[20] M.M. Stack, J.S. James, Q. Lu, Erosion-corrosion of chromium steel in a rotating cylinder electrode system: some comments on particle size effects, Wear 256 (2004) 557-564.

[21] M.M. Stack, H.W. Wang, Simplifying the erosion-corrosion mechanism map for erosion of thin coatings in aqueous slurries, Wear 233-235 (1999) 542-551.

[22] M.M. Stack, H.W. Wang, W.D. Munz, Some thoughts on the construction of erosion-corrosion maps for PVD coated steels in aqueous environment, Surf Coat. Technol. 113 (1999) 52-62.

[23] K.R. Trethewey, J. Chamberlain, Corrosion for Science and Engineering, 2nd ed., Longman Scientific and Technical, 1995, pp. 341-347.

[24] M.G. Gee, N.J. McCormick, L. Newton, R. Darling, Analysis of the size and shape of abrasives, NPL Report No.: DEPC MPE 009, National Physical Laboratories, Teddington, UK, February 2005. 
[25] M. Matsumura, Y. Oka, H. Hiura, M. Yano, The role of passivating film in preventing slurry erosion-corrosion of austenitic stainless steel, ISU Int. 31 (1991) 168-176.

[26] W. Tsai, J.A.C. Humphrey, I. Cornet, A.V. Levy, Experimental measurement of accelerated erosion in a slurry pot tester, Wear 68 (1981) 289-303.

[27] S. Turrene, M. Fiset, J. Masounave, The effect of sand concentration on the erosion of materials by a slurry jet, Wear 133 (1989) 95-106.

[28] B.W. Madsen, Measurement of erosion-corrosion synergism with a slurry wear test apparatus, Wear 123 (1988) 127-142.

[29] X. Hu, A. Neville, The electrochemical response of stainless steels in liquid solid impingement, Wear 258 (2005) 641- 648 .

[30] M.M. Salama, An alternative to API 14E erosional velocity limits for Sand-Laden fluids, J. Energy Resour. Technol. 122 (2000) 71-77.
[31] P. Roberge, B.C. Syrett, Erosion-Corrosion, NACE International, 2004

[32] R.S. Lynn, K.K. Wong, H.M. Clark, On the particle size effect in slurry erosion, Wear 149 (1991) 55-71.

[33] I.M. Hutchings, Tribology-Friction and Wear of Engineering Materials, Edward Arnold, 1992.

[34] R.C. Barik, J.A. Wharton, R.J.K. Wood, K.S. Tan, K.R. Stokes, Erosion and erosion-corrosion performance of cast and thermally sprayed nickelaluminium bronze, Wear 259 (2005) 230-242.

[35] Y.G. Zheng, Z.M. Yao, W. Ke, Erosion-corrosion resistant alloy development for aggressive slurry flows, Mater. Lett. 46 (2000) 362-368.

[36] T. Hodgkiess, A. Neville, S. Shrestha, Electrochemical and mechanical interactions during erosion-corrosion of a high velocity oxy-fuel coating and a stainless steel, Wear 233-235 (1999) 623-634. 